\title{
FORMACIÓN HISTÓRICA DE LA ESTRATIFICACIÓN SOCIAL EN AMÉRICA LATINA ${ }^{1}$
}

\section{ESTRATIFICACIÓN Y ESTRUCTURA SOCIAL}

A comienzos de la segunda mitad del siglo XX, las opciones de desarrollo en América Latina pasaron a ser no sólo objeto de preocupación de las esferas gubernamentales y políticas, sino también tema de atención preferente del pensamiento sociológico. El aporte de la sociología en este campo fue señalar la importancia que había adquirido en nuestros países el conocimiento de su estructura social, considerando su doble carácter de condicionante esencial de la dinámica de transformación que estaban experimentando y de determinante de la especificidad que representaban como sociedad. A este respecto suelen citarse tradicionalmente los estudios pioneros de T.R. Crevenna ${ }^{2}$ y una serie de estudios de carácter nacional realizados poco más tarde. Para los propósitos de este artículo, más que hacer referencia al

1 Este artículo se basa en el trabajo sobre "Estructura social y estilo de desarrollo en América Latina”, elaborado en conjunto con Rodrigo Baño para la División de Desarrollo Social de la CEPAL, Texto extraido de la Revista de la CEPAL, $\mathrm{N}^{\circ}$ 50, agosto de 1993.

2 T.R. Crevenna, Materiales para el estudio de la clase media en América Latina, Washington D.C., Unión Panamericana, 1950-1951. 
contenido sustantivo de los diversos estudios, conviene ofrecer una visión retrospectiva - por cierto muy sucinta- de los criterios interpretativos referidos a la estructura y estratificación social de la región, puesto que hoy en día, ante las profundas transformaciones ocurridas, parece urgente redefinir esos criterios y proponer nuevos enfoques que expliquen la dinámica de cambio actual.

Entre los autores que se han referido al tema sólo se seleccionarán algunos que se consideren representativos de las orientaciones generales, aunque somos conscientes de que toda selección implica el riesgo de caer en omisiones importantes. No obstante, podrá admitirse que existe cierto consenso en considerar a Gino Germani ${ }^{3}$ como un autor que ejerció profunda influencia en el conocimiento de la estructura y estratificación social de América Latina; si bien sus estudios se refieren específicamente a la Argentina, el marco interpretativo que elaboró se utilizó ampliamente en la región. Para Germani, la preocupación fundamental era comprender las particularidades que presentaba, en países como los nuestros, el innegable proceso de modernización al cual se asistía. Las formas de la estratificación social expresaban las modalidades de dicho proceso que, si bien tenía ciertos rasgos universales, presentaba también notorias especificidades. Con fines expositivos, Germani contrastaba dos tipos de sociedad: una de carácter tradicional, en donde los estratos sociales correspondían a formas estamentales claramente diferenciadas, la movilidad social tendía a ser casi inexistente o muy escasa y regía para los individuos el principio de adscripción; en lo fundamental, el estatus social quedaba determinado por el nacimiento. En contraste, la sociedad moderna presentaba pluralidad de estratos - fenómeno que también podía darse en las sociedades tradicionales, por ejemplo en un sistema de castas-, pero lo más importante era que las fronteras entre los diversos estratos tendían a difuminarse, y el conjunto de la sociedad adquiría el carácter

3 Gino Germani, Estructura social de los argentinos, Buenos Aires, Raigal, 1955; Política y sociedad en una época de transición: de la sociedad tradicional a la sociedad de masa, Buenos Aires, Paidós, 1968. 
de un continuo. Por otra parte, Germani suponía una alta movilidad social, a la que contribuían los procesos de migraciones geográficas. En este tipo de sociedad, el criterio de adscripción en la definición del estatus y en la asignación de los roles sociales era reemplazado por el desempeño o el logro individual, debido a la importancia que estaban adquiriendo. Los dos tipos de sociedad señalados constituían, por cierto, esquematizaciones que en algún sentido cumplían funciones heurísticas semejantes a los tipos ideales en donde la realidad podía presentar aproximaciones mayores o menores.

Germani también recurría a otro tipo de esquematizaciones que pudiesen servirle como modelo comparativo respecto a América Latina. Así, hacía mención a la evolución de la estratificación social en los países en donde se había originado el capitalismo. En el esquema postulaba la existencia de tres fases o etapas en el desarrollo capitalista, a las cuales correspondían - también de modo esquemático - tres tipos de sociedades. La primera fase se caracterizaba por la existencia de un sector primario aún importante, un sector secundario básico y un sector terciario relativamente pequeño. Los grupos sociales en esa etapa de desarrollo correspondían a una clase alta, aún con poder pero declinante; una burguesía, que ya pasaba a ser el grupo principal; y un proletariado urbano, que empezaba a constituir formas de agrupación política; al mismo tiempo constataba un debilitamiento relativo de los sectores rurales, como así mismo de la denominada "pequeña burguesía".

La segunda fase, considerada de transición, se caracterizaba por la caída del sector primario y la expansión del sector secundario; el sector terciario había crecido con el desarrollo de servicios modernos. Con el aumento del sector secundario y el crecimiento y transformación del terciario habían adquirido significación —en el tipo de sociedad que se había constituido- los grupos que desempeñaban funciones de dirección y los que componían el segmento burocrático.

El conjunto de los sectores medios había aumentado, pero se apreciaba cierta inestabilidad en su constitución, puesto que junto 
al surgimiento de nuevos grupos, otros perdían significación. El proletariado urbano, que debido a la expansión del sector secundario también había crecido, lograba mayores niveles de organización, pero así mismo de diferenciación interna, y empezaba a distinguirse con nitidez la llamada aristocracia obrera. En términos generales, también se percibía un aumento de la movilidad social.

La tercera fase del capitalismo —en los países en que éste se originó- se caracterizaba por un sector primario reducido, un sector secundario estabilizado y una notoria expansión del sector terciario. Un rasgo importante de esta etapa sería la separación de la propiedad del control de las empresas y actividades económicas, con el surgimiento consiguiente de un importante sector tecnocrático. Respecto a los sectores medios, se habría producido cierta estabilización en contraste con la fase de transición anterior. Con relación al conjunto de los asalariados, se establecía una distinción según el carácter manual o no manual del trabajo que realizaban. La sociedad toda participaría de un movimiento general "hacia delante", que sería percibido tanto por los distintos grupos sociales como por las personas individualmente. El resultado sería una conformidad social generalizada, salvo en algunos grupos "marginales".

Las dos esquematizaciones reseñadas, que como se ha señalado tienen para Germani un propósito heurístico, puesto que pueden servir como modelos comparativos respecto de América Latina, llevan implícita una teoría de la modernización. De este modo lo que se postula respecto a la estratificación y a la estructura social forma parte de dicha teoría. Además, y sobre todo en el segundo esquema, referido a las fases del desarrollo capitalista, los elementos importantes del análisis de la estratificación social son la transformación estructural de las economías y los cambios concomitantes en la estructura social, tanto respecto al surgimiento, declinación o desaparición de lo que podrían llamarse "grupos funcionales", como a las relaciones de poder que se establecen entre los distintos grupos y clases.

Germani elaboró para la Argentina y para América Latina una serie de esquemas que muestran las particularidades históricas 
de sus procesos de cambio y transformación. Según este autor, en América Latina, a diferencia de lo ocurrido en el capitalismo original, el proceso de modernización tuvo lugar bajo la conducción de "oligarquías modernizadoras", cuya base de poder económico estaba ligada a una economía de exportación de productos primarios y no preferentemente a la industrialización; los grupos tradicionales que en cierta medida perdieron poder fueron los que no estaban vinculados a la economía exportadora. Otro rasgo importante del proceso de modernización es el significado que adquirieron los sectores medios, en especial los ligados a los organismos burocráticos, sobre todo públicos, pero también privados; estos grupos encabezaron los movimientos políticos y sociales de carácter multiclasista que enfrentaron a la oligarquía. El proletariado organizado, salvo algunas excepciones, era relativamente débil, por lo que se sumó a los movimientos señalados sin un claro perfilamiento de su autonomía e identidad. El proceso de industrialización sustitutiva que tuvo lugar en muchos países de la región significó una mayor incorporación e integración de los sectores medios. En las etapas más avanzadas del proceso, a la clase alta, constituida por la vieja burguesía terrateniente y la vieja burguesía industrial, se sumó una nueva burguesía vinculada a la industria; los sectores medios fueron más dependientes de la estructura social existente, y el proletariado creció, pero también, y en forma significativa, empezaron a crecer los grupos marginales.

Teniendo en cuenta todo lo expuesto, Germani, enfrentado específicamente al problema de cómo estudiar y analizar la estratificación social en casos concretos, planteó la necesidad de abordar el conocimiento de la estructura ocupacional de la población, la jerarquía que se atribuía a las diferentes ocupaciones de acuerdo con las pautas socioculturales dominantes, y el tipo de vida que caracterizaba a las diferentes ocupaciones, considerando tanto el nivel económico como otras características, en especial los niveles de instrucción. Asignó importancia también a la autoidentificación de las personas en las diferentes ocupaciones con una u otra clase social, y a los distintos sistemas de actitudes, normas 
y valores que correspondían a los diversos grupos ocupacionales y que marcaban diferencias entre ellos.

Podría decirse, entonces, que la estructura ocupacional se constituía en el fundamento básico de la estratificación aplicable a América Latina, cuyos componentes aparecían como sigue: a) clases altas y medias rurales: patrones, empresarios y empleadores, del sector primario, y "ayuda familiar" y empleados del mismo sector; b) clases altas y medias urbanas: patrones, empresarios, empleadores de la industria, el comercio y los servicios; "ayuda familiar" en las empresas del jefe de familia; trabajadores por cuenta propia de la rama "gráfica-prensapapel"; los que figuran en los rubros "comercio mayorista", "cambios", "escritorio", "espectáculos públicos", "hotelería", "servicios sanitarios", "transporte terrestre"; los empleados y cadetes de los sectores secundario y terciario, y los rentistas, jubilados y pensionados no incluidos en la población activa y cuyas características corresponden a la clase media; c) clases populares rurales: obreros y aprendices del sector primario y trabajadores por cuenta propia del mismo sector, $\mathrm{y} \mathrm{d}$ ) clases populares urbanas: obreros y aprendices del sector secundario, comercio y servicios, y trabajadores por cuenta propia de todas las ramas industriales y del comercio y de los servicios.

En distintos escritos, ${ }^{4}$ José Medina Echavarría abordó el tema de la estructura y estratificación sociales de América Latina. Su preocupación era determinar la particularidad histórica de la estructura social latinoamericana, que consideraba clave tanto para comprender las modalidades de su desarrollo como para conocer el modo en que podían enfrentarse los desafíos de la modernización, que en sus características más generales y universales parecían casi ineludibles. Estaba consciente, pues, de la variación histórica de los sistemas de estratificación y de que los esquemas relativamente simples eran sólo expresivos de un determinado

4 José Medina Echavarría, Aspectos sociales del desarrollo económico, serie conmemorativa del XXV aniversario de la CEPAL, Santiago de Chile, CEPAL/ILPES, febrero de 1973; La urbanización en América Latina, informe de los editores, Buenos Aires, Solar-Hachette, 1967; Consideraciones sociológicas sobre el desarrollo económico en América Latina, Buenos Aires, Solar-Hachette, 1964. 
período en los países latinoamericanos, como lo fue el predominio del sistema de haciendas. Reconocía, sin embargo, que incluso en ese período, en las ciudades encontraban asiento nuevos grupos, de comerciantes, profesionales liberales y otros, que mostraban una relativa - aunque creciente- autonomía frente a la oligarquía tradicional. Diversos procesos que incidieron en la transformación histórica tornaron cada vez más complejo el sistema de clases y grupos sociales. El surgimiento de nuevos estratos, que pasaron a desempeñar papeles sociales significativos, determinó por último la crisis del sistema tradicional, en una secuela de problemas y desafíos. Los cambios producidos en la estratificación se vinculaban, a su juicio, de manera casi directa con los cambios en la estructura económica. Era perceptible para él la tendencia al predominio de la industria y los servicios a expensas del sector llamado primario, principalmente la producción agropecuaria, lo que había traído como consecuencia la formación de nuevas clases altas —más propiamente burguesía - y sectores medios y populares, particularmente obreros. El hecho que destacó con fuerza fue el crecimiento cada vez mayor de las ciudades, y la progresiva reducción de los grupos rurales, que pasaron a engrosar las filas de las clases urbanas.

Medina Echavarría hace referencia a la formación de una sociedad industrial, que por cierto no se repite pari passu en América Latina, pero que configura un patrón que dentro de ciertos límites alcanza validez general. En este sentido, señalaba que se produce una transformación de la clase alta, que de ser la aristocracia tradicional pasa a ser la burguesía moderna; surge un nuevo sector en creciente expansión, el de las clases medias, que ocupa una posición de singular importancia en la estructura industrial, y las clases inferiores se transforman, al surgir el obrero urbano, que reemplaza a los antiguos artesanos y supera a la vez a los campesinos.

Para este autor, el cambio de estructura implicaba en sí mismo un acentuado grado de movilidad social, vinculado al crecimiento de las capas medias y también al desplazamiento rural-urbano, lo que, a su juicio, suponía un considerable grado de ascenso 
social. Esta movilidad podía llamarse con propiedad movilidad estructural. También planteaba que la nueva sociedad industrial era una sociedad de clases abiertas, y por lo tanto a la movilidad estructural se agregaba una movilidad que le era propia. En su concepción de la sociedad industrial aparecían conceptos como los encontrados en Germani: el principio de la adscripción tendía a ser reemplazado por el del mérito, y el de la sociedad estamental o de castas por el de la sociedad de clases. Subrayaba que en la sociedad industrial la igualdad de oportunidades - por lo menos en teoría - era indispensable para lograr la distribución óptima de la población en las diferentes actividades especializadas. Podría decirse que esa igualdad aparecía así como un requisito funcional de la nueva sociedad. Pensaba que el predominio de cierto tipo de racionalidad, la racionalidad instrumental, era inherente a la sociedad industrial. La división del trabajo en dicha sociedad obedecía ahora al principio electivo de tal racionalidad. Por cierto advertía que entre la proclamada igualdad de oportunidades y la posibilidad efectiva de ascenso quizá existiera un hiato, pero siempre tendría que darse alguna posibilidad de libre circulación de los individuos con el fin de permitir su incorporación al sistema especializado de tareas.

No está de más subrayar que, para Medina Echavarría, los rasgos mencionados de la sociedad industrial adquieren la connotación de un "tipo-ideal", la sociedad tradicional. Los contrastes son esclarecedores para la comprensión de la particularidad de las sociedades latinoamericanas. Así, puso de relieve varios rasgos decisivos como, por ejemplo, el grado de especialización de las instituciones. Mientras en la sociedad tradicional la mayoría de las funciones se concentra en unas pocas instituciones, en la sociedad industrial dominan las instituciones especializadas, cada una con una tarea limitada y específica. Además, en la primera, el tipo de acción predominante se encuentra fijado, prescrito, para cada situación de una manera más o menos rígida. En cambio, en la segunda rige el tipo de acción que cabe denominar deliberada; la sociedad ofrece diversos criterios que deben tomarse en cuen- 
ta al realizar la elección, pero lo esencial es la elección misma (la deliberación) que está impuesta por la estructura social.

$\mathrm{Al}$ autor citado le interesaba particularmente el comportamiento social frente al desarrollo y el cambio, y a este respecto veía una particular contraposición entre la sociedad tradicional y la industrial:

La sociedad tradicional y la industrial se oponen radicalmente en su actitud respecto al cambio. La tradicional exalta más bien la herencia del pasado. La sociedad industrial, por el contrario, valora y estimula toda mudanza, es decir, el cambio se encuentra institucionalizado. $^{5}$

También acotaba otro hecho de singular importancia respecto a la sociedad industrial, que atañe a la organización política y su fundamento. Consideraba que en el pasado la sociedad industrial estuvo vinculada a una forma política determinada, la democracia liberal. Estaba consciente de que tal juicio no era plenamente aceptado por muchos estudiosos y que por tanto estaba sujeto a revisión. Sin embargo, creía que cualquiera fuera el tipo de estructura política que la sociedad industrial adoptara, este tipo de sociedad parecía exigir grados más amplios de participación política en sectores cada vez más extensos de la población. Independientemente de lo controvertido de las aseveraciones anteriores, destacan en ellas por lo menos dos preocupaciones: la actitud más o menos favorable frente al cambio, y el tema de la participación política y sus formas. A ambas preocupaciones, que fueron medulares en un momento histórico, la sociología quería ofrecer alguna respuesta.

Utilizando la tipología señalada, Medina Echavarría destacó en su momento como una especificidad latinoamericana la permeabilidad o flexibilidad del sistema de dominación tradicional. Si bien es cierto que los grupos dominantes tradicionales, u oligarquías en términos latos, se habían resistido a los cambios que

5 J. Medina Echavarría, La urbanización en América Latina, op. cit, p. 49. 
tendían a desplazarlos, en cierta medida se habrían acomodado a ellos para poder subsistir. La adopción del cambio, sin embargo, por la forma en que se había hecho, habría distorsionado el proceso de modernización. Por lo demás, dado el mecanismo de la adopción distorsionadora, la crisis del sistema tradicional no desembocó en una ruptura total. A pesar del surgimiento de una estratificación social más compleja, la dominación tradicional no desapareció del todo, sino que, transformándose, mantuvo en parte su vigencia. Se negaba a desaparecer, y en cierta medida lo logró.

Estrechamente vinculada a lo expuesto está la noción de dualismo estructural. Este dualismo es, por cierto, un rasgo característico de una fase de transición, en este caso, de la sociedad tradicional a la sociedad moderna. Se expresa también por el hecho de que en un mismo momento coexisten países con distinto grado de desarrollo. Pero más importante aún es la coexistencia en un mismo país de zonas más próximas al tipo de civilización industrial junto a otras más cercanas al tipo tradicional; de ciudades modernas y de otras tradicionales, de zonas rurales que son el prototipo de lo tradicional y de otras que adquieren los rasgos de la sociedad industrial. En América Latina, dada la "flexibilidad distorsionadora" antes mencionada, se hacen extraordinariamente complejas e intrincadas las relaciones entre lo moderno y lo tradicional.

Esta coexistencia de lo tradicional y lo moderno se traduce en asincronías que se manifiestan en distintas esferas de la vida social. Hay, por ejemplo, cierta asincronía en el proceso de cambio de las actitudes y comportamientos de los distintos estratos, lo que en alguna medida explica el papel que desempeñan las elites. La transformación "suele empezar en determinados sectores de las elites urbanas y propágase luego en dirección descendente hacia las diferentes capas de la población, desde las más elevadas hasta las más bajas". ${ }^{6}$ Pero la asincronía no se refiere sólo al compor-

6 Ibid., p. 54. 
tamiento de las personas, sino que se manifiesta también en las instituciones, de donde se deriva que

[...] si las instituciones no se transforman con la misma velocidad - y a veces en la misma dirección_, en un mismo lugar y en un determinado instante existirán diversas instituciones más o menos cercanas a los tipos tradicional o industrial; [de este modo] [...] es posible que la estructura técnicoeconómica se haya trasformado en la dirección requerida por el tipo industrial, mientras que otras esferas se encuentran rezagadas. $\mathrm{O}$ al contrario. En todo caso estas asincronías pueden encontrarse en diferentes partes de la estructura social. ${ }^{7}$

La preocupación principal del autor citado, en relación con este tema, se centró en sus posibles repercusiones en la opción de desarrollo de los países latinoamericanos. El supuesto fundamental era que las estructuras técnico-económicas de tipo industrial requerirían motivaciones adecuadas a ellas y por lo tanto no podrían funcionar con las motivaciones que eran peculiares de la sociedad tradicional. Como se ha señalado, las asincronías podían darse tanto en el comportamiento de las personas como en las instituciones y también en las relaciones entre ambas. Así, dadas ciertas transformaciones en la estructura ocupacional, podían no producirse los cambios necesarios en las motivaciones, actitudes y sentimientos de las personas afectadas. También era posible que las actitudes hubieran evolucionado en el sentido requerido por la sociedad industrial, pero que existiese estancamiento en el aparato técnico-económico, educacional, político, etc. En términos concretos, es posible que las aspiraciones, las actitudes hacia el consumo, el estilo de vida — advertía Medina Echavarría - se aproximen a los de la sociedad industrial, pero que la producción permanezca en una fase de escaso e insuficiente desarrollo. El aporte de Medina Echavarría en este campo estriba, pues, en haber abordado el terna de la transformación de la

$7 \quad$ Ibid., p. 53. 
estructura y la estratificación sociales, y sus particularidades en América Latina, y en haber puesto de relieve la necesidad de ligar los cambios estructurales que afectan a grupos y estratos sociales con los valores y actitudes que orientan el comportamiento de los grupos en cuestión.

Para los autores más cercanos al pensamiento marxista, el problema de la estratificación social —o más propiamente el de las clases sociales- aparecía muy ligado a las peculiaridades del desarrollo capitalista de la región, y éste — constataban- difería bastante de lo que podría considerarse el modelo original. Es el caso, por ejemplo, de Florestán Fernandes, ${ }^{8}$ quien señalaba la dificultad de referirse a una sociedad de clases en América Latina si se tenía en cuenta que el capitalismo en la región no era en gran medida producto de la evolución interna, y que por sus propios rasgos carecía de capacidad para crear condiciones de desarrollo autónomo y de crecimiento autosostenido. Por consiguiente, las clases sociales —entendiendo por tales las que surgen en un sistema capitalista — no comprenden a la totalidad de la población; gran parte de ella constituye "categorías sociales" más que clases. $\mathrm{El}$ "sistema de clases" es entonces reducido. Aunque entre ellas hay enormes diferencias, se superponen a otras categorías sociales —como las de los marginales, los desposeídos, los miserables-y disfrutan de cierto privilegio, puesto que a menudo son sólo ellas las que pueden participar en las decisiones fundamentales. Además, se da el hecho de que las clases que existen no se perciben a sí mismas como tales y tienden a negar ese carácter a las demás categorías sociales.

Según Fernandes, en el caso de América Latina se da una mezcla de diversos estadios de evolución económica, por lo menos en el momento que él analiza, de modo que no se puede hablar de una universalización de las formas de mercado capitalista. Un hecho particularmente relevante es que en segmentos importantes

8 Florestán Fernandes, Sociedades de clanes e subdesenvolvimiento, Rio de Janeiro, Zohar, 1968; Capitalismo dependente e clases sociais na América Latina, Rio de Janeiro, Zohar, 1973. 
de la economía —en el sector agrario, por ejemplo, pero también en otros sectores- es posible apropiarse del trabajo sobre bases no estrictamente capitalistas, esto es, en términos de un mercado de trabajo. De aquí deriva que la diferencia fundamental pase a ser la posesión o no posesión de bienes. La categoría de los poseedores comprende a los sectores capitalistas propiamente tales y a otras fuerzas que tienen ciertos rasgos estamentales, como los sectores altos rurales. De hecho, el autor citado distingue una clase alta rural y una clase alta urbana, compuesta por industriales, burgueses grandes comerciantes, profesionales que ocupan cargos directivos o tienen alta calificación, y otros. Distingue también una clase media urbana, que aunque no es estrictamente "poseedora", asocia sus intereses a los de los poseedores; en ella reconoce una clase media tradicional y una clase media moderna. En la categoría de los no poseedores, formada por grupos muy heterogéneos, se incluyen los que están incorporados a economías de subsistencia o a estructuras arcaicas del sistema económico y los que empiezan a constituirse estrictamente como proletarios asalariados.

Pese a haber tropezado con dificultades en esta tarea, los autores de inspiración marxista se esforzaron por aplicar conceptos teóricos tomados de esa corriente de pensamiento en el análisis de la estructura y estratificación sociales latinoamericanas. Muchos de ellos se concentraron en el análisis de determinados grupos, como los empresarios o los sectores obreros; pero otros, como De Ipola y Torrado, ${ }^{9}$ también intentaron aplicar esquemas más globales. Ambos autores desarrollaron un esquema teórico basado en la noción de la división social del trabajo en la sociedad capitalista. A partir de ella postulan la existencia de una relación de producción que aparece como determinante. Esta relación de producción es —en el lenguaje marxista— una relación de explotación que da lugar a dos grandes grupos: uno compuesto por los trabajadores directos y el otro por aquellos que se apro-

9 Emilio de Ipola y Susana Turrado, Teoría y método para el estudio de la estructura de clases sociales, Santiago de Chile, Programa de Actividades Conjuntas ELASCELADE (PROELCE)-Facultad Latinoamericana de Ciencias Sociales (FLACSO), julio de 1976. 
pian del trabajo excedente. Se trata por consiguiente de un grupo "explotado" y un grupo "explotador"; ambos constituirían las clases sociales. Distinguen, además de la relación de producción determinante, relaciones de producción determinadas que, sobre la base de la primera, se establecen entre los agentes de la producción y los medios de producción que intervienen en un proceso social de producción históricamente dado. Estas relaciones son fundamentalmente: a) las relaciones de propiedad, que pueden tomar las formas de propiedad privada individual, propiedad privada colectiva e incluso de propiedad privada social; por esta última se entiende aquella en que el portador de la misma toma la forma de la unidad de la clase de todos los propietarios (en este sentido, la comúnmente llamada "propiedad privada social"). b) las relaciones de posesión, que establecen la relación de ciertos agentes de la producción con los medios de producción que intervienen en el proceso de producción. A través de esa relación tales agentes disponen del poder de dirección y de coordinación del proceso productivo, asegurando de ese modo su funcionamiento. c) el control técnico, que es la relación de ciertos agentes de la producción con los medios de producción que intervienen en un proceso de trabajo; mediante esa relación los agentes disponen de la capacidad de poner en acción esos medios de producción. d) la detentación, que se refiere a la relación de los productores directos con los medios de producción, en tanto esos medios intervengan directamente en el trabajo. Cada una de estas relaciones supone la relación inversa, esto es, de no-propiedad, no-posesión, no-control técnico y no-detentación.

La división social del trabajo determinaría la distribución de los agentes de la producción, en función tanto de las relaciones de producción determinantes (relaciones de explotación) como de las relaciones de producción determinadas (de propiedad, posesión, control técnico y detentación). A la primera corresponderían las clases sociales y a la segunda las capas sociales, que serán el subconjunto de agentes que en el interior de una clase social ocupan posiciones jerárquicas diferentes. 
Esta división social del trabajo se especifica mediante la "división del trabajo social", que determina la distribución de los agentes de la producción según los diferentes subprocesos y sectores de actividad; esto permite distinguir fracciones de clase como, por ejemplo, burguesía industrial, burguesía comercial, financiera, etc. También tiene lugar un proceso de división técnica del trabajo, que consiste en la asignación de las tareas y funciones dentro de cada proceso de trabajo, haciendo abstracción de las relaciones sociales de producción.

Por último, pueden distinguirse "unidades de producción", que son propiamente unidades económicas, como empresas, bancos, centros comerciales, etc., con una jerarquía de funciones y de poderes de decisión como, por ejemplo, de dirección, control o ejecución. Junto a los procesos económicos de un modo de producción determinado tienen lugar también procesos no económicos, los principales de los cuales son los procesos jurídico-políticos y los ideológicos, que aseguran las condiciones de la reproducción del proceso de producción. Esos procesos tienen sus propios aparatos; por ejemplo, en el caso de los procesos jurídico-políticos, las fuerzas armadas, los tribunales, los partidos políticos; en el caso de los procesos ideológicos, la familia, la escuela, las instituciones religiosas, los medios de comunicación masiva; las personas vinculadas a los procesos no económicos forman categorías sociales.

En conformidad con lo expuesto, el esquema de la estructura social en un modo de producción clasista estaría dado por un proceso social de producción que establece relaciones antagónicas de explotación, esto es, conflicto de clases. El proceso social de producción se descompone en un proceso directo de producción, que da origen a capas y fracciones de clase. Es necesario, para una cabal comprensión, distinguir el proceso dominante, que es el que asegura las condiciones principales de la reproducción; en el capitalismo es el proceso de circulación, y sobre todo el mercado de trabajo. Por último, están los procesos de naturaleza no económica, jurídico-políticos e ideológicos, que aseguran las condiciones secundarias de reproducción del proceso social de producción. 
De acuerdo con estos autores, las clases sociales tienden a una mayor o menor diferenciación interna según el tipo de desarrollo capitalista. Por ejemplo, si la clase capitalista se distingue porque tiene la propiedad y la posesión, en tanto que la clase obrera tiene el control técnico y la detentación, en la fase monopólica del capital la primera se divide entre propietarios y ejecutivos (posesión), y a su vez, en la segunda se separa el control técnico de la detentación (mano de obra).

La estratificación propuesta, como es evidente, puede ser referida a un sistema de clases y aplicar a una sociedad determinada las hipótesis que se derivan de la teoría de la relación de clases, en especial las que atribuyen la dinámica de la transformación al conflicto de clases.

Autores como Filgueira y Geneletti ${ }^{10}$ también trataron el problema del conflicto social al abordar el tema de la estratificación y la movilidad, pero lo consideraron de carácter fundamentalmente distributivo. Para ellos "la estratificación alude, en sentido general, a la manera en que los individuos tienen acceso a los bienes sociales disponibles". ${ }^{11}$ Tales bienes son preferentemente el ingreso, la educación, el prestigio, el poder y la riqueza. Señalan que los patrones de estratificación social constituyen las causas y consecuencias mayores del conflicto entre los individuos y los grupos existentes en la sociedad. Por movilidad entienden el cambio en los patrones de distribución de los bienes sociales. Distinguen entre la movilidad individual, que comúnmente se mide por la diferencia de ocupación entre padre e hijo, y la movilidad estructural, que se origina debido al aumento de algunas ocupaciones respecto de otras con estatus diferente. Este tipo de movilidad estaría, entonces, determinado por cambios en la estructura productiva, y es el que interesa a estos autores y constituye el objeto de su trabajo. En América Latina ha habido una importante movilidad demográfica, principalmente debido a la

10 Carlos Filgueira y Carlo Geneletti, Estratificación y movilidad ocupacional en América Latina, Cuadernos de la CEPAL, No 39 (E/CEPAL/G. 1122), Santiago de Chile, octubre de 1981.

11 Ibid., p. 2. 
migración rural-urbana, que por cierto ha implicado cambios en la estructura ocupacional. De ahí que para analizar el cambio en el perfil de dicha estructura Filgueira y Geneletti hayan considerado necesario referirse como punto de partida a las transformaciones sectoriales de la economía, estableciendo las distinciones clásicas entre sector primario, secundario y terciario. El objetivo era ver cómo repercutían esas transformaciones en el volumen relativo de los estratos socioeconómicos que componen la población económicamente activa.

El esquema de estratificación que dichos autores elaboraron distingue varios estratos, en cada uno de los cuales se aglutinan diversos grupos ocupacionales. El esquema es el siguiente: a) Estratos medio y superior en ocupaciones secundarias v terciarias: empleados en la industria, el comercio y los servicios; personal de categorías superiores en la industria, el comercio y los servicios; empleados por cuenta propia en el comercio, y empleados, vendedores, oficinistas, en la industria, el comercio y los servicios. b) Estrato inferior en ocupaciones secundarias: asalariados; trabajadores por cuenta propia y familiares no remunerados. c) Estrato inferior en ocupaciones terciarias: asalariados; trabajadores por cuenta propia y trabajadores familiares no remunerados. d) Estratos medio y superior en ocupaciones primarias. e) Estrato inferior en ocupaciones primarias: asalariados; trabajadores por cuenta propia y trabajadores familiares no remunerados. f) Otros.

De los análisis estadísticos que realizaron, cuyos datos alcanzaban hasta el año 1970, Filgueira y Geneletti deducen que en ese momento empezaban a manifestarse indicios de una redefinición de la estructura de estratos, a juzgar por las líneas de ruptura que generaba el surgimiento de un sector moderno en las distintas ramas de la actividad económica. No obstante el pausado crecimiento de este sector en términos ocupacionales, los autores advierten sobre la importancia sociológica de dicha transformación, puesto que generaba grupos que podrán ser decisivos en la formación e identificación de algunos estratos, en especial los compuestos por ejecutivos, gerentes y personal de dirección, lo que modificaría la composición global de las clases medias. También 
advierten que, por el mismo motivo anterior, podría surgir entre los grupos de trabajadores manuales una "aristocracia obrera".

Señalan también estos autores que los estratos medios inferiores y los profesionales dependientes han experimentado el mayor crecimiento (una de cada cuatro personas ocupadas pertenece a esos estratos). Sin embargo, presentan un rasgo de extrema importancia, que es la incongruencia de su estatus ocupacional con su estatus educacional, ya que por lo general tienen un alto nivel de educación, pero a la vez sólo acceden a bajos ingresos. Existe también una gran diferencia de estatus entre quienes desempeñan ocupaciones no manuales bajas y los que desempeñan ocupaciones no manuales altas. Los primeros formarían una especie de subproletariado de clase media, pero, a pesar de eso, no se identifican subjetivamente con el proletariado propiamente tal.

Con referencia al comportamiento de los sectores medios, los autores referidos señalan que experimentaron un fuerte crecimiento — en especial la burocracia—, a lo que acompañó una expansión educacional que los favoreció. En la mayoría de los países latinoamericanos hubo una fase de desarrollo de las dimensiones de modernización social, concretamente la urbanización y la educación, lo que contribuyó a la integración de los grupos mencionados. Ante estos hechos, los autores afirman que existen "pautas de gratificación diferida", que se caracterizan por la aceptación de un estado de cosas desfavorable en función de una expectativa futura de mejoramiento. Sin embargo, advierten que si en el largo plazo se agotaran las posibilidades de mantener un equilibrio razonable entre las aspiraciones y su satisfacción, tendería a producirse una acumulación de tensiones peligrosa. Las incongruencias de estatus indicadas no sólo repercuten en las conductas individuales y en las tensiones -individuales o colectivas - que se pueden generar, sino que influyen también en otras dimensiones como, por ejemplo, en la eficacia misma del funcionamiento del sistema económico. Para los autores citados existiría en grado creciente una fuerte inadecuación entre los niveles y tipos de conocimiento y las necesidades ocupacionales. Prueba de ello serían los porcentajes crecientes de educación 
universitaria que se registran en personas que desempeñan actividades administrativas bajas, o de niveles de enseñanza media en actividades de servicios que requieren escasa calificación. Todo esto indicaría que en el estilo de desarrollo vigente es cada vez mayor la subutilización de los recursos humanos disponibles. Por otra parte, debido a que la asincronía entre el desarrollo del sistema educacional y el de la estructura productiva generaría una “devaluación de la educación”, la inversión en educación de los individuos tendría que ser cada vez más alta para que pudiesen obtener los mismos niveles ocupacionales o de ingresos.

En suma, el modelo de movilidad estructural dominante en la región se ha caracterizado por una importante reducción porcentual de las actividades primarias, sobre todo las rurales; por la estabilidad de las actividades urbanas de bajo nivel y por el crecimiento de los estratos medios y altos. Sin embargo, la fuerza de trabajo proveniente de la disminución regular e intensa del sector primario es absorbida principalmente por el sector terciario, y el sector secundario pareciera no tener una capacidad de absorción similar a la disminución del sector primario. En la región ha habido movilidad social, pero ésta ha sido sólo parcial, puesto que su dinámica estaría bloqueada. Consideran los autores citados que la movilidad social existente "sólo es posible si no se afecta fuertemente la distribución básica de los recursos económicos”. Existiría un bloqueo estructural a la movilidad social, atribuible a la estructura de estratificación ocupacional vigente y sus distorsiones.

\section{CARACTERIZACIÓN DE LOS DISTINTOS GRUPOS SOCIALES}

La sociología latinoamericana no sólo ha establecido ciertos parámetros interpretativos respecto a la estructura y estratificación social de la región, sino que también ha producido numerosos estudios sobre grupos sociales específicos que comprenden tanto monografías como enfoques con pretensiones teóricas más amplias. Dada la cantidad de esos estudios, no es posible intentar en estas páginas una síntesis más o menos exhaustiva, por lo que 
sólo se presentarán algunos ejemplos que se consideran significativos. Además, los trabajos que describen las características de los distintos grupos en su mayoría tenían una validez restringida en el momento en que se hicieron, por lo que todo intento de generalización es riesgoso. No obstante, como nuestra intención es precisamente destacar cambios y transformaciones, lo que en algún momento se reconoce como característica de un grupo tiene valor para contrastar lo que en otro momento se postula, dándose de este modo por lo menos una cierta indicación de los rasgos de la transformación.

\section{LA OLIGARQUÍA Y LAS ELITES}

En primer lugar se hará referencia a la denominada oligarquía, término con el que a menudo se ha caracterizado a los grupos altos que tradicionalmente tienen en sus manos el poder.

Uno de los estudios más detallados sobre este grupo es el de Bourricaud,${ }^{12}$ que, aunque se refiere específicamente al Perú, contiene aportes generalizables. La oligarquía y el dominio oligárquico se fundan, según dicho autor, en una situación de patrimonialismo casi perfecto, que se caracteriza por el control que ejerce el "patrón" en las áreas rurales a través de la hacienda y por la constitución de "clientelas" en el medio urbano. Cabe recordar que Medina Echavarría también destacaba en sus escritos la importancia del sistema de haciendas en la configuración de un modelo de comportamiento sociocultural en América Latina y que además se refería al sistema de clientela como uno de los modos particulares de relación político-social en los países de la región. Ambos autores resaltan la importancia que adquirían para estos grupos las conexiones familiares. Bourricaud muestra cómo mediante las conexiones familiares la oligarquía lograba controlar amplios sectores de la economía. Teniendo como centro las actividades agrícolas, sus familias dominaban buena

12 François Bourricaud, "Notas acerca de la oligarquía en el Perú, José Matos-Mar", en La oligarquía en el Perú, Buenos Aires, Amorrortu, 1969. 
parte del comercio exterior, influían poderosamente en algunos medios de comunicación importantes y diversificaban sus intereses como, por ejemplo, en la construcción. La oligarquía, para Bourricaud, es un grupo que logra un alto grado de control de la riqueza existente. Su rasgo característico es la estrecha relación que logra establecer entre el poder económico y el poder político.

Graciarena y Franco ${ }^{13}$ advertían un cambio en el control del poder, que estaría pasando de la oligarquía a un nuevo grupo de poder de tipo elitario. Según estos autores, un hecho notable en los países latinoamericanos es la ampliación de la base de reclutamiento social de las personas que ocupan posiciones de poder. Este reclutamiento, en la forma oligárquica — como ya se señaló- era preferentemente de base familiar; típicamente la oligarquía estaba formada por gente emparentada o muy relacionada con incorporaciones clientelistas. En cambio, los integrantes de estos nuevos grupos que llegan a posiciones de poder proceden de una base social más heterogénea. Sin embargo, la mayoría de ellos adquieren modos de ser y de pensar similares, o al menos compatibles, y esto se explicaría porque tienen en común una socialización, una experiencia social y una ideología afines.

Estos autores no restringen la condición elitaria a los sectores altos de la sociedad. Ese tipo de poder se da en distintos segmentos, existiendo, por ejemplo, elites empresariales, sindicales, religiosas, militares o de tecnócratas civiles, y es posible que se establezcan entre ellas complejas relaciones. La complejidad y heterogeneidad de las elites derivarían de la propia heterogeneidad de la estructura económica. En el aparato productivo coexistiría un núcleo moderno y dinámico con grandes sectores de economía arcaica: además, habría un bloque de empresas semimodernas con niveles más bajos de eficiencia y productividad que las de los centros dinámicos, a los cuales se subordinarían. A cada uno de estos tipos de empresas - de diferentes grados de modernidad - corresponderían patrones de estratificación social diver-

\footnotetext{
13 Jorge Graciarena y Rolando Franco, Formaciones sociales y estructuras de poder en América Latina, Madrid, Centro de Investigaciones Sociológicas, 1981.
} 
sos, y de allí resultaría la creciente complejidad e incongruencia de la estructura social.

Por lo tanto, podría establecerse una distinción entre oligarquía y elite en función de los distintos orígenes de sus reclutamientos y de sus respectivas bases de poder. En el primer caso, la base sería agraria, aunque con importantes ramificaciones; en cambio, las elites no serían ajenas a los procesos de modernización e industrialización, ni a la presencia de clases medias numerosas y significativas. Pero, advierte Graciarena ${ }^{14}$ en otro estudio, el hecho es que en América Latina las elites son oligárquicas; el grupo de poder, por su reclutamiento, tiene características fundamentalmente elitarias, pero sus políticas obedecen a los patrones oligárquicos.

\section{LOS SECTORES EMPRESARIALES}

Otro grupo ampliamente estudiado es el de los empresarios. Sin embargo, las investigaciones se han centrado en su mayor parte en el empresario industrial. Este hecho es comprensible por la importancia que tuvo en el proceso de desarrollo latinoamericano el surgimiento de una economía industrial de consideración. Cuando se hacía referencia a los orígenes del empresariado industrial de América Latina, por lo general se le reconocía una doble procedencia. Un grupo de empresarios provendría del ascenso social de inmigrantes extranjeros, y el otro, de la diferenciación económica de las antiguas clases productoras del período exportador. De esta forma el empresariado industrial habría nacido escindido y con fuertes limitaciones para tomar conciencia de sus intereses particulares. No obstante, en ambos casos el grupo de referencia ideológica habría sido la vieja oligarquía: a veces porque ésa era su procedencia y otras por un afán imitativo que les proporcionaba los símbolos de la integración. En general, los empresarios tendieron a vincularse con los grupos de ma-

14 Jorge Graciarena, Poder y clases sociales en el desarrollo de América Latina, Buenos Aires, Paidós, 1967. 
yor poder económico-social, de modo que las expectativas de una "alianza industrializadora" - idealmente constituida por los empresarios industriales, los sectores medios y los obreros-fue muchas veces sólo la aspiración de ciertos ideólogos o un hecho circunstancial. Sobre todo los empresarios más importantes se identificaban más con los intereses de los grupos que manejaban el poder económico-social.

Otro hecho de bastante importancia - y que incidió en lo anterior- fue la formación, desde hacía ya mucho tiempo, de grandes conglomerados económicos que incorporaron todo tipo de actividades y vincularon estrechamente la industria con otros sectores, como la banca, por ejemplo, controlados por grupos más tradicionales. Además, especialmente en las grandes empresas, la dependencia externa - aunque las actividades se dirigieran al mercado nacional — era considerable y se expresaba en las áreas financiera, tecnológica e incluso del capital accionario. Así, la vinculación de intereses tendió a privilegiar todo aquello que posibilita tal conexión y los intereses que la hacían viable.

Por cierto que también era importante el grupo de los pequeños y medianos empresarios, que si bien a veces mostraban comportamientos algo antagónicos al de los grandes empresarios, se encontraban por lo común en una posición de acentuada subordinación respecto a ellos, lo que les impedía extremar los conflictos. Por otra parte, al no estar en condiciones de atender las demandas de sus asalariados, procuraban concertar alianzas con los grupos de mayor poder con el fin de contener las presiones. Además, la pequeña y mediana industria tendió a verse muy afectada en los momentos negativos del ciclo económico, y su eficacia económica, por diversos motivos, no mostró signos alentadores. Según un estudio realizado en Chile por G. Campero, ${ }^{15}$ entre 1967 y 1979 la pequeña industria disminuyó el número de sus establecimientos en un 10,5\% y su valor agregado en $27,6 \%$.

15 Guillermo Campero, Los gremios empresariales en el período 1970-1983: comportamiento sociopolítico y orientaciones ideológicas, Santiago de Chile, Instituto Latinoamericano de Estudios Transnacionales (ILET), 1984. 
Los sociólogos interesados en la conducta de los empresarios y su incidencia en las modalidades del proceso de desarrollo se preocuparon particularmente en analizar su capacidad de creación y de innovación y su habilidad para enfrentar los riesgos, entre otros rasgos. En muchos estudios se mostraba que, salvo algunas excepciones y coyunturas muy especiales, los empresarios no se caracterizaban por su disposición a invertir en nuevas empresas, asumiendo el riesgo. En general, parecían inclinarse más bien por aprovechar las ventajas que ofrecía el mercado, y por esta razón en muchos casos predominaban en ellos comportamientos más propios del espíritu comercial y financiero. Su a menudo escaso interés por innovar obedecería a que gran parte de ellos operaba en mercados cautivos. Muchas de las investigaciones realizadas muestran que el comportamiento empresarial se caracterizó, durante largos períodos, por su tendencia a la adaptación más que por una opción transformadora. Se percibía que los empresarios tendían a ceñirse a las posibilidades de una demanda que obedecía a una determinada estructura social. Así, la estructura productiva reproducía los patrones de la demanda socialmente estructurada.

\section{LOS SECTORES MEDIOS}

Además del papel de los empresarios en el proceso de desarrollo, la sociología latinoamericana se ha preocupado en particular del comportamiento de los sectores medios, teniendo en cuenta su rol en el proceso político y en el proceso de modernización en general. En el trabajo citado de Filgueira y Geneletti se dedica atención preferente a esos grupos, porque a juicio de los autores el cambio experimentado en la proporción del total de la población económicamente activa que representa la clase media es un buen indicador de los cambios producidos en el conjunto de los patrones de estratificación social, aparte de ser un factor clave para comprender la movilidad social. Dada la heterogeneidad de ese grupo y la amplitud del concepto de clase media, sus investigaciones pusieron énfasis en la composición por estratos de 
las distintas ramas de actividad, puesto que sustentan la tesis de que el crecimiento de la clase media está vinculado al cambio de composición de la población económicamente activa por rama de actividad.

Gran parte de quienes han estudiado el tema tienden a señalar que en la mayoría de los países de América Latina la expansión de los sectores medios ha sido desproporcionada respecto al grado de desarrollo de las fuerzas productivas. Entre las causas de esa hipertrofia se señala la convergencia de una serie de procesos, como la urbanización, el desarrollo de la educación y el proceso de burocratización. La percepción mayoritaria es que el factor fundamental habría sido precisamente la expansión del aparato estatal.

Autores como Ratinoff ${ }^{16}$ han tratado de distinguir diversas fases en la evolución histórica de estos sectores, teniendo en cuenta especialmente los tipos de comportamiento que se dan en cada una de ellas. Así, distinguen una fase de ascenso, que se caracterizaría por la búsqueda y el logro de apoyo de los sectores populares a las propuestas políticas de los sectores medios; por una importante capacidad de creación institucional; por la formulación de políticas e ideologías favorables a la intervención del Estado y por la introducción de cambios en los planos económico, social, cultural y político. Y una segunda fase, que denominan "fase de compromiso", cuyo rasgo predominante sería la intención de garantizar las propuestas ya logradas.

Graciaren $a^{17}$ postula también la existencia de un ciclo histórico largo en la comprensión de los grupos medios, en donde el eje es su grado de autonomía respecto a otros grupos. Esa autonomía habría sido muy escasa en los comienzos de la sociedad latinoamericana, esto es, después de la Independencia; más tarde, durante los primeros decenios del siglo XX, habría ido en ascenso, hasta alcanzar su grado máximo en diversos momentos,

\footnotetext{
16 Luis Ratinoff, "Los nuevos grupos urbanos: las clases medias", en S.M. Lipset y A. Solari (eds.), Elites y desarrollo en América Latina, Buenos Aires, Paidós, 1967.

17 Jorge Graciarena, Poder y clases sociales, op. cit.
} 
según los países. A partir de ahí, comenzó a declinar hasta llegar a un nivel nuevamente muy bajo, en el momento en que el autor escribió el estudio referido.

En el proceso descrito, Graciarena distingue dos grupos principales. Uno, el de las "clases medias residuales", se habría formado en la época colonial y durante el siglo XIX, en estrecha vinculación con las clases altas y con altos niveles de dependencia estructural y de prestigio respecto a ellas. Este grupo habría estado muy vinculado a la economía tradicional y ha tendido a declinar, pero sin perder toda su significación, puesto que hoy aparece ligado principalmente a ciertos sectores de la burocracia pública, como la judicatura, el servicio diplomático y algunos niveles de la educación. Su comportamiento estaría orientado por los valores de la clase alta. Un segundo grupo, el de las "clases medias emergentes", sería producto del desarrollo económico, y sus bases principales se encontrarían en el sector moderno de la economía: la industria, el comercio y los servicios. Este grupo habría tenido mayor autonomía que el anterior y habría promovido el desarrollo económico, enfrentándose en esa tarea con la oligarquía y las clases medias tradicionales. Este conflicto, sostiene Graciarena, fue importante y marcó un momento esencial en el proceso histórico latinoamericano, pero más tarde tendió a desaparecer.

Muchos autores sostienen que parte importante de los sectores medios ha disfrutado de condiciones casi parasitarias promovidas por regímenes que utilizaron o utilizan los recursos del Estado para ampliar exageradamente el número de empleos burocráticos; que ofrecieron créditos baratos para las empresas y los profesionales, lo mismo que para la vivienda y el consumo; que promovieron políticas asistenciales públicas que beneficiaban principalmente a esos sectores, y otras medidas similares. Al tomar conciencia de esta situación de privilegio, tales grupos — sostienen los analistas - habrían adoptado actitudes de defensa de un statu quo que les resultaría ventajoso. Por otra parte, se señala que tienen un peso significativo en los esquemas de poder existentes, debido a su número e influencia social, que se 
acrecienta por el papel que tienen en el aparato de Estado tecnócratas y burócratas salidos de sus filas. Por todo lo anterior, los sectores medios habrían contribuido a configurar los rasgos de algunos de los estilos de desarrollo que han tenido vigencia en la región. A pesar de lo señalado, algunos autores reconocen que, dado que estos sectores han logrado niveles de educación relativamente altos, lo que se traduce en formación y capacidad profesional, habrían ayudado en cierta medida al desarrollo de la racionalidad técnica, con una influencia considerable en los niveles de productividad económica.

El problema de la heterogeneidad interna de los sectores medios ha captado el interés de los analistas, quienes han utilizado diversos criterios para establecer sus diferencias. Filgueira y Geneletti, por ejemplo, distinguen entre los que desempeñan ocupaciones no manuales de estatus alto y de estatus bajo. Estos últimos habrían experimentado un mayor crecimiento, lo que implicaría cierta "proletarización" de estos estratos, aunque esto no necesariamente significa una identificación subjetiva con los sectores populares. Pero junto al crecimiento de sectores medios relativamente pauperizados surge una clase media "moderna". Se plantea, entonces, el interrogante de si ese crecimiento es susceptible de mantenerse constante y de qué condiciones deberían darse para que ese hecho suceda en cada país. Cualquiera que sea la respuesta a este interrogante, es un hecho que la mayor parte de los analistas coincide en señalar la importancia de los grupos tecnocráticos vinculados a esos estratos. El propio desarrollo, señalan, más el efecto de demostración de los países avanzados del sistema internacional, ha obligado a crear una estructura de nivel técnico alto. La posición que esos grupos ocupan significa que pueden incidir de manera importante en la configuración de ciertos rasgos del estilo de desarrollo. O’Donnell, ${ }^{18}$ por ejemplo, señala que los tecnócratas de alto nivel de las instituciones más grandes tienen ciertos rasgos de formación y socialización comunes y que establecen entre sí vinculaciones que redundan en un

18 Guillermo O'Donnell, Modernización y autoritarismo, Buenos Aires, Paidós, 1972. 
reconocimiento mutuo y en características de conducta similares, cualquiera sea el sector en que actúen. Su comportamiento estaría orientado por cierta definición de lo racional, lo adecuado y lo técnicamente eficaz. Fernandes, ${ }^{19}$ al parecer pensando más bien en los grupos recién señalados, apunta que los sectores medios son los portaestandartes de la ultramodernización y que en esa esfera tienen las mejores posibilidades de autovaloración en el mercado; en la modernización estaría el elemento específico de sus intereses y actuación de clase. Los cambios en la ponderación de los distintos sectores dentro de los estratos medios tienen consecuencias para la ideología del conjunto. Según Graciarena ${ }^{20}$ los sectores medios han abandonado sus postulaciones ideológicas iniciales y, por consiguiente, han debilitado sus posibilidades de acción sobre las demás clases. Considera que su poder se basó siempre en la ampliación del control del Estado y por ello, al aceptar ideologías que restan legitimidad a la intervención estatal, minan la base de aquél, y la dirección efectiva de los procesos económicos queda en manos de las grandes empresas.

\section{LOS OBREROS}

Según los datos de que se dispone, entre 1961 y 1980 los estratos que componen la clase obrera adquirieron un peso cada vez mayor en casi todos los países. No obstante, en comparación con el resto de la población económicamente activa, ese peso no adquiría aún carácter decisivo y variaba mucho de un país a otro. Así, por ejemplo, en Argentina los obreros representaban el 27,5\% de la población económicamente activa; en Chile, el 25\%, y no alcanzaban a más del 19\% en Venezuela y Panamá, al 17,5\% en México, al $16 \%$ en Colombia, al 15\% en Brasil y a menos del $15 \%$ en Perú.

Otro hecho que cabe destacar es la heterogeneidad de su composición interna. Pero ésta no obedece tanto a diferencias

19 Florestán Fernandes, Sociedades de clanes e subdesenvolvimiento, op. cit., 1968.

20 Jorge Graciarena, Poder y clases sociales, op. cit. 
en el tipo de ocupación o actividades que desempeñan, como sucede en los sectores medios, sino a otros factores. La primera diferencia que notaron los investigadores del tema fue la existencia de una clase obrera "antigua" y otra "nueva". Esta última se habría formado a raíz de los procesos de migración interna y de expansión acelerada de la industria en el transcurso del proceso de sustitución de importaciones. La mayor parte de los estudios constituye en una especie de "tipo ideal" a la vieja clase obrera, que en rigor correspondía más a los países de la costa atlántica de América Latina, específicamente Brasil, Uruguay y Argentina y, con mayor propiedad a las ciudades en que había habido alguna actividad industrial importante con anterioridad a la sustitución de importaciones. De este modo, se postulaba que la clase obrera tenía un fuerte componente de migración europea, en particular italiana, española y portuguesa, la que contaba con una relativa tradición obrera y ciertos niveles de calificación, aunque estaba próxima a algunos rasgos artesanales e ideologías propias del movimiento obrero de sus países de origen. Las investigaciones posteriores enmendaron muchos de estos supuestos. Primero se señaló que esa experiencia — como ya se indicó- correspondía sólo a algunos países; que incluso en el caso en que la migración europea había sido importante, no necesariamente la mayoría del contingente emigrado tenía experiencia obrera, y se destacó la importancia de los antecedentes rurales de los inmigrantes. Se hizo ver que mucho de lo que se afirmaba se refería a grupos relativamente pequeños que habían cumplido una función como grupo dirigente y que se estaba confundiendo el carácter de la elite de dirección con las características del conjunto. Estos rasgos típicos ideales que se atribuían a la vieja clase obrera se utilizaron para contrastarlos con los que eran propios de los nuevos contingentes formados por la migración interna y la expansión del sector industrial. Válida o no la comparación, la caracterización de los nuevos obreros tenía cierto valor en sí misma.

Los rasgos que más a menudo se destacaban respecto a ellos eran su bajo nivel de instrucción y, además, su baja calificación, puesto que por sus orígenes rurales no habían tenido una expe- 
riencia semiindustrial, ni tampoco artesanal. Su procedencia se consideró al inicio como uno de los elementos clave de su conducta y características, pero se mostró que en algunos países — por ejemplo en Chile, según Gurrieri- ${ }^{21}$ esta aseveración demasiado rotunda debía analizarse cuidadosamente, puesto que el migrante rural tenía también cierta experiencia en ámbitos urbanos de provincia, claro está que de menor tamaño. Otro hecho interesante que señala Gurrieri es que, por lo menos en Chile, la formación por migración de los sectores obreros no era una experiencia nueva sino que formaba parte de la historia del origen de la clase obrera. No obstante, pensando en el conjunto de los países latinoamericanos, después de la Segunda Guerra Mundial la migración interna pasó a ser un fenómeno masivo, y los nuevos contingentes aparecieron en el momento de la expansión del consumo popular, lo que influyó en su tipo de demanda. La incorporación a la vida urbana, en términos de lo que en su momento significaba, por ejemplo, acceso a la vivienda, la educación y las prestaciones sociales, prevalecía sobre las reivindicaciones referidas más específicamente a la vida de trabajo.

En cuanto al cambio que se estaba operando, éste no sólo afectaba a los grupos obreros sino que incidía en el conjunto de la sociedad. El sistema normativo anterior ya no tenía la misma validez, y esto afectó a los grupos obreros. La formación de una identidad de clase pareció siempre un hecho difícil, en especial en lo que respecta a la definición de intereses comunes; la solidaridad que se daba se relacionaba preferentemente con grupos primarios. Todo lo anterior contribuyó a explicar lo que parecía ser la conducta política más generalizada, esto es, constituirse en masas disponibles y fácilmente manipulables.

Las afirmaciones hechas en torno al sector obrero tenían un rango de generalización muy amplio y era necesario establecer

21 Adolfo Gurrieri, Consideraciones sobre los sindicatos chilenos, Santiago de Chile, Instituto Latinoamericano y del Caribe de Planificación Económica y Social (ILPES), 1968. 
algunas diferencias importantes. Di Tella ${ }^{22}$ distinguió dos estratos principales en el sector obrero: el estrato bajo y el estrato alto. El primero es el que más se aproxima a la clase obrera nueva, ya mencionada, por su bajo nivel cultural y escasa calificación. Di Tella señalaba en ellos su tendencia a un tipo de "personalidad autoritaria". Su perspectiva social sería confusa y mostrarían cierta disposición a participar en fenómenos de masas, en donde existiría la ilusión de una participación directa no mediada por organización alguna. El estrato alto estaría formado, en cambio, por individuos de mayor nivel de educación y calificación, razón por la cual tendrían a menudo la posibilidad de llegar a ser dirigentes, y con ello mayores posibilidades de movilidad social, tanto personal como familiar; esta circunstancia los acercaría a los sectores medios, de los cuales internalizaron su pauta de valores. La distancia social que los separa de los estratos obreros bajos los llevaría a interpretar los intereses del conjunto a partir de sus propias condiciones; su identidad con los valores de los sectores medios dificultaría la comunicación con el resto de la clase obrera e incluso la cabal comprensión de sus problemas. El hecho es que ni en los estratos bajos ni en los altos existiría una clara identidad de clase.

La diferenciación entre obreros calificados y no calificados pasó a ser un elemento importante en el análisis de la estratificación interna del sector. De acuerdo con diversos estudios, en São Paulo, por ejemplo — una de las ciudades más industrializadas de Brasil_-, en la década de 1970 y posteriormente, los obreros no calificados no mejoraron su nivel de vida, situación que contrastó con la de los obreros calificados, quienes además vieron aumentar su salario real. Incluso en los momentos de regresión salarial, ésta fue mucho más significativa en los obreros no calificados. Se consideraba que la distancia que mediaba entre la masa no calificada y el grupo obrero con mejor inserción en la vida industrial había repercutido en muchos casos en la orientación del movi-

22 Torcuato di Tella, El sistema político argentino y la clase obrera, Buenos Aires, Editorial Universitaria de Buenos Aires (Eudeba), 1964. 
miento sindical e incluso en algunas manifestaciones políticas. Se postulaba que ambos estratos no compartían los mismos valores e intereses y que el grupo más calificado tendía a ser percibido corno una elite privilegiada.

\section{LOS CAMPESINOS}

En los análisis que se han hecho del campesinado en América Latina es importante destacar la influencia de los enfoques antropológicos, tanto en la forma de describir su estructura como en el estudio de los rasgos de su comportamiento. Además, muchas de las primeras formulaciones corresponden a investigadores estadounidenses, lo que incluso se evidencia en la terminología utilizada. Redfield, ${ }^{23}$ por ejemplo, distinguía en el campesinado a la pequeña comunidad aislada, al peasant y al farmer. Peasant son aquellos que tienen un control sobre la tierra que les permite $-y$ esto es significativo- mantener e incluso desarrollar en común un modo de vida tradicional; la agricultura es el fundamento de ese modo de vida y no se la concibe principalmente como una inversión, por cuanto una parte de la producción se vende en el mercado, ni tampoco principalmente como una empresa. El farmer, por el contrario, tiene una orientación empresarial y la agricultura es su negocio.

Algunos investigadores latinoamericanos, corno Quijano, ${ }^{24}$ destacan en la definición del campesinado la relación de poder en la cual se insertan. El campesinado - señalan- es aquel segmento de la población de las áreas rurales que pertenece a las capas económica y socialmente dominadas, esto con prescindencia del rol específico que puedan desempeñar, y puede incluir a jornaleros, colonos, minifundistas, pequeños comerciantes, artesanos, estudiantes, entre otros. Lo anterior no significa el olvido de estas

23 Robert Redfield, Peasant Society and Culture, Chicago, The University of Chicago Press, 1956.

24 Aníbal Quijano, "Movimientos campesinos contemporáneos en América Latina", en S.M. Lipset y A. Solari (eds.), Elites y desarrollo en América Latina, Buenos Aires, Paidós, 1967. 
diferenciaciones, sino la conformación de una categoría amplia e inclusiva.

Landesberger ${ }^{25}$ trató de resumir los rasgos comunes a las distintas definiciones disponibles del campesinado con el siguiente resultado: se entiende como campesino el "cultivador rural", esto es, aquella persona ligada al trabajo de la tierra o muy cercana a ella; su orientación es dual, tanto hacia la familia como hacia el mercado, pero no percibe su posición como la de quien maneja un negocio con el fin de obtener el máximo de provecho; su conducta está referida a una comunidad, por lo general un conjunto limitado de familias que comparten las mismas normas y valores y que ocupan una posición subordinada en un orden jerárquico, económico y político. Para el propio Landesberger lo esencial, sin embargo, es que se trata de un cultivador rural de posición política y económica baja y sus características particulares deben definirse empíricamente en cada caso.

Stinchcombe ${ }^{26}$ en cambio, intentó establecer una tipología diferenciada de campesinos según los tipos de empresas agrícolas a las que estuvieran vinculados. Esta tipología abarca diversas categorías, basadas en el poder de tomar decisiones productivas y sobre la distribución de los beneficios; en el valor de la tierra; en la disposición, por parte del propietario, de poder policial sobre los trabajadores, o en el hecho de tener con ellos relaciones de parentesco; en el volumen de capital requerido para hacer funcionar la empresa, con exclusión de la tierra, y en el grado de racionalización técnica incorporado a la empresa. Basándose en estos criterios, Stinchcombe identificó distintos tipos de empresas agrícolas. Uno es la bacienda, perteneciente a un sistema aún de rasgos señoriales y características precomerciales, y que se caracteriza por la distribución dual de la tierra. Una parte se divide en pequeños lotes que están en manos de los campesinos, quienes

25 Henry Landsberger, Contemporary Latin American Peasant Movements, Ithaca, Cornell University Press, 1969.

26 Arthur L. Stinchcombe, "Agricultural Enterprise and Rural Class Relation”, en American Journal of Sociology, vol. 67, Chicago, University of Chicago Press, 1961-1962. 
practican en ella una agricultura de subsistencia; la otra constituye el dominio señorial y su producción se dirige al mercado. Esta tierra es cultivada por los campesinos antes mencionados y a menudo el trabajo se constituye basado en obligaciones consuetudinarias. Tanto el precio del trabajo como el de la tierra son bajos, y el poder del terrateniente casi absoluto. La producción no es abundante y la eficiencia es muy baja. La producción denota la separación que existe entre el terrateniente y el campesinado; frecuentemente el primero es un propietario ausentista que desarrolla actividades políticas en la ciudad; el campesinado, en cambio, vive al margen de ese mundo y en condiciones de apatía, atraso y carencia de derechos políticos.

Otro tipo de empresa agrícola es la plantación. Esta empresa corresponde a una gran propiedad capitalista dedicada a cultivos que por lo común exigen varios años para su maduración y gran cantidad de mano de obra, y puede también requerir otro tipo de inversiones de largo plazo como, por ejemplo, en maquinarias. En ella se hace uso intensivo de mano de obra, frecuentemente de carácter estacional. Según Stinchcombe, la clase dominante en este tipo de empresas se preocupa de evitar que surja la pequeña propiedad e incluso la sofoca, en el caso de que esto suceda. El control técnico —apunta— está en manos del grupo social mencionado.

La estancia, para este autor, es una empresa capitalista que practica la ganadería o la agricultura extensiva y cuya mano de obra es preferentemente asalariada. La tierra por sí misma tiene poco valor de cambio y la mano de obra es barata, fluctuante, móvil, con escasos lazos familiares, y vive en campamentos colectivos. Hay también - agrega-empresas basadas en el arrendamiento de tierras que son explotadas por familias. En estos casos, el terrateniente propiamente tal es un rentista que entrega su tierra a cambio de un pago, que puede realizarse en dinero o en especie o en una combinación de ambas modalidades. Las tierras que utilizan estas empresas tienen alta productividad y elevado precio de mercado; hacen uso intensivo del trabajo, pero su mecanización agrícola es de escaso desarrollo; la mano de obra —además de 
la familia que se puede utilizar - es barata: el ciclo agrícola dura un año o menos y no existen economías de escala apreciables en factores distintos del trabajo. El contacto social entre los rentistas y los campesinos es muy escaso, de modo que ambos grupos tienen estilos de vida muy discrepantes.

Por último, Stinchcombe se refiere a la pequeña propiedad familiar, que corresponde al productor. En general sus costos son relativamente estables, pero sus mayores problemas derivan del proceso de comercialización y tiene conflictos con los intermediarios, comerciantes y acreedores. La comunicación dentro del grupo es escasa.

Los estudios citados sobre el campesinado de la región no sólo sirvieron para caracterizar las diferencias dentro de él y, por lo tanto, la estructura rural existente, sino que además — sobre todo en los años sesenta y principios de los setenta— pretendían proporcionar los elementos básicos para explicar los movimientos campesinos que surgieron a raíz del proceso de reforma agraria que tenía lugar en muchos países. El objetivo era comprender la orientación de esos movimientos y el tipo de nuevas estructuras que podían generar, teniendo en cuenta la tradicional vinculación de los campesinos con la tierra. Siendo así, la investigación se orientó preferentemente a las características de los distintos movimientos campesinos que en ese momento se consideraban importantes.

\section{MARGINALIDAD Y SECTOR INFORMAL}

En los primeros trabajos de investigación referidos a las personas que hoy se tiende a agrupar bajo el concepto de sector informal se utilizó más bien la noción de marginalidad.

A partir de 1950, y como resultado del proceso de migración masiva rural-urbana, empezó a formarse en las grandes ciudades cierto tipo de aglomeraciones que se caracterizaban sobre todo por la instalación de viviendas improvisadas en terrenos que eran "ocupados" de modo espontáneo por estos nuevos habitantes. Al estudiar esos asentamientos urbanos se observó que no sólo 
se componían de migrantes de origen rural, sino que a menudo también formaban parte de ellos los expulsados de la propia ciudad. La preocupación por estos segmentos de la población puso muy pronto en evidencia que también otros grupos, que a veces eran más antiguos en la ciudad, vivían en condiciones similares de precariedad, como era el caso de los habitantes de los tugurios y conventillos urbanos. Sin embargo, lo impresionante era la amplitud y el carácter masivo del nuevo fenómeno.

La preocupación inicial por la marginalidad ecológica condujo rápidamente a una preocupación por la condición social y las características de estos grupos de población. Dada la importancia que se atribuía al fenómeno de la migración, la discusión giró en torno a la permanencia en tales grupos de características propias del mundo rural, de donde se postulaba que provenían, y a cuáles eran su forma y capacidad de adaptación a las nuevas condiciones. En un primer momento se tendió a considerar la situación de estos grupos como propia de una fase de transición entre el mundo rural y el urbano. Sin embargo, algunos autores, como J. Matos-Mar, por ejemplo, señalaron que en situaciones de migración masiva, como la del Perú, se trataba de una especie de ruralización del mundo urbano, lo que se condensaba en el título de un escrito sobre la Serranización de Lima. Los clásicos estudios de $\mathrm{O}$. Lewis tendieron a mostrar que más que una inserción en el mundo urbano tendía a constituirse una verdadera "cultura de la pobreza”.

Rosenblüth, ${ }^{27}$ en un estudio pionero que realizó en poblaciones marginales de Santiago de Chile, mostró la reducida participación de estos grupos en los beneficios del desarrollo económico, su escaso acceso a las instituciones que son propias del Estadonación y, por consiguiente, la marginalidad política, económica y social que les afectaba: la dimensión de la marginalidad adquiría un significado más amplio que el puramente ecológico. Así mis-

27 Guillermo Rosenblüth, Problemas socioeconómicos de la marginalidad y la integración urbana: el caso de "las poblaciones callampas" en el Gran Santiago, memoria de grado, Santiago de Chile, Universidad de Chile, Facultad de Ciencias Económicas, Escuela de Economía, 1963. 
mo, según los estudios del Centro para el Desarrollo Económico y Social de América Latina (DESAL), esos grupos de pobladores tendían a no participar de las normas y valores de la sociedad, su inserción en el mundo del trabajo era permanentemente precaria, no tenían acceso a las decisiones importantes, tampoco participaban de modo efectivo en la solución de sus propios problemas. Este tipo de trabajos llevó a una preocupación más específica por la forma de inserción económica de estos grupos. En especial, algunos autores que tenían mayor sensibilidad por los enfoques de índole marxista iniciaron una discusión sobre la función económica de tales grupos. J. Num y otros acudieron a la categoría de ejército de reserva, aunque en sucesivas elaboraciones - debidas en gran parte a una polémica en que, además de los mencionados, participó F.H. Cardoso- se trató de adecuar la noción de ejército de reserva a las condiciones particulares de las economías dependientes como las latinoamericanas. Las críticas a la aplicación de esa noción enfatizaban el carácter de "población excedente" que tenían esos grupos respecto de la economía y hacían una advertencia respecto al problema de la incapacidad de absorción del sistema económico vigente. Se postulaba que el mismo proceso de desarrollo y modernización en América Latina tenía capacidad para desorganizar formas económicas anteriores, pero carecía de capacidad para absorber a los desplazados en formas productivas.

Cabe hacer notar que en los estudios que empezaron a preocuparse por los modos de inserción económica de estos grupos, se abandonaron los primeros supuestos de que la condición de marginalidad era un momento de una fase de transición de la vida rural a la urbana, y que tales grupos terminarían por insertarse de modo "normal" en esta última. La preocupación se volvió, entonces, hacia los rasgos del sistema económico y sus características negativas. Muchos de los trabajos posteriores se vincularon a estudios del Programa Regional de Empleo para América Latina y el Caribe (PREALC), en que se articuló la noción de desigualdad 
con la de economía informal. Tokman ${ }^{28}$ señaló la incapacidad del sector moderno de la economía para absorber mano de obra al ritmo requerido y, al mismo tiempo, hizo énfasis en la heterogeneidad de la estructura productiva.

Esta heterogeneidad determinaba la existencia de mercados de trabajo diferenciados. Gran parte de los nuevos integrantes de la fuerza de trabajo urbana, o sea, aquellos que provenían del propio crecimiento vegetativo o de la migración, no encontraban ocupación en el sector moderno. Su búsqueda de trabajo se orientaba, entonces, hacia otros estratos productivos: en ellos el mercado de trabajo funcionaba de manera distinta y la demanda de mano de obra no dependía del proceso de acumulación dentro del sector, sino que el nivel de empleo lo determinaban el excedente de fuerza de trabajo y la posibilidad que ofrecía el mercado de producir o vender algo que generara algún producto.

Según Tokman se generan básicamente dos tipos de mercado de trabajo: uno formal y otro informal. En el primero, los puestos de trabajo se ubican en las empresas organizadas y en los servicios personales que requieren los estratos de mayores ingresos. A estos puestos acceden las personas más calificadas y con mayor experiencia en cada categoría profesional. Por su parte, el mercado de trabajo informal lo constituyen aquellos que desarrollan actividades por cuenta propia, los que trabajan en empresas pequeñas y los que prestan servicios personales de baja productividad. Añade que en este tipo de mercado predominan las actividades por cuenta propia, en que el "empresario" es a la vez "trabajador". En gran parte debido a esto, el salario no es la forma de remuneración más generalizada, y casi no existe una acción estatal reguladora de las relaciones de trabajo, tanto en materia de legislación como de control de las mismas.

En el estudio citado, Tokman dice que, a pesar de estas definiciones, es difícil determinar empíricamente el tamaño del

28 Víctor Tokman, "Dinámica del mercado de trabajo urbano: el sector informal urbano en América Latina”, en Reyes Kaztman (ed.), Fuerza de trabajo y movimiento laboral en América Latina, México, Colegio de México, 1979. 
sector informal. Sin embargo, existen varias alternativas para su medición. Una de ellas considera preferentemente la posición ocupacional e incluye dentro de este sector a los ocupados por cuenta propia, a los que prestan servicios domésticos y a los ocupados en unidades productivas de menos de cuatro personas. La segunda alternativa considera el nivel de ingreso, e incluye en el sector a todos aquellos que perciben un ingreso mínimo fijado exógenamente. Y la tercera alternativa considera informales a todos aquellos que no hacen aportes al seguro social, con excepción de los profesionales y los ocupados en establecimientos de más de cinco personas; a este grupo se agregarían también las empleadas domésticas. Pese a las dificultades de su medición, hacia 1975 se calculaba, a partir de los estudios existentes en diversas ciudades de la región, que el sector informal ocupaba entre el $46 \%$ y el $50 \%$ de la mano de obra urbana. Respecto a las características de su composición, se concluía que la participación de la mujer era mayor que en el resto de los sectores de la economía, aun excluyendo el servicio doméstico; que en él se concentran los trabajadores más jóvenes y los más viejos y también los de menor educación. Respecto a las actividades, alrededor del $80 \%$ al $85 \%$ de los ocupados en este sector se vinculan a actividades de comercio, servicios profesionales y actividades que se catalogan como "industriales", como fabricación de calzado, confecciones y preparación de alimentos. Un rasgo importante que se desprende de los estudios es que los vendedores ambulantes que, como señala Tokman, para muchos representan la imagen física del sector informal, en la mayor parte de los países no exceden el 10\% de la ocupación de este sector; y las actividades "industriales" en países como México, San Salvador y Paraguay, ocupan un 15\% del total del mismo sector.

\section{BIBLIOGRAFÍA}

Bourricaud, François, "Notas acerca de la oligarquía en el Perú, José Matos-Mar", en La oligarquía en el Perú, Buenos Aires, Amorrortu, 1969. 
Campero, Guillermo, Los gremios empresariales en el período 19701983: comportamiento sociopolítico y orientaciones ideológicas, Santiago de Chile, Instituto Latinoamericano de Estudios Transnacionales (ILET), 1984.

Crevenna, T.R., Materiales para el estudio de la clase media en América Latina, Washington D.C., Unión Panamericana, 1950-1951.

De Ipola, Emilio y Susana Turrado, Teoría y método para el estudio de la estructura de clases sociales, Santiago de Chile, Programa de Actividades Conjuntas ELAS-CELADE (PROELCE)-Facultad Latinoamericana de Ciencias Sociales (FLACSO), julio de 1976.

Di Tella, Torcuato, El sistema político argentino y la clase obrera, Buenos Aires, Editorial Universitaria de Buenos Aires (Eudeba), 1964.

Fernandes, Florestán, Sociedades de clanes e subdesenvolvimiento, Rio de Janeiro, Zohar, 1968.

, Capitalismo dependente e clases sociais na América Latina, Rio de Janeiro, Zohar, 1973.

Filgueira, Carlos y Carlo Geneletti, Estratificación y movilidad ocupacional en América Latina, Cuadernos de la CEPAL, Nº 39 (E/ CEPAL/G. 1122), Santiago de Chile, octubre de 1981.

Germani, Gino, Estructura social de los argentinos, Buenos Aires, Raigal, 1955.

, Política y sociedad en una época de transición: de la sociedad tradicional a la sociedad de masa, Buenos Aires, Paidós, 1968.

Graciarena, Jorge, Poder y clases sociales en el desarrollo de América Latina, Buenos Aires, Paidós, 1967.

Graciarena, Jorge y Rolando Franco, Formaciones sociales y estructuras de poder en América Latina, Madrid, Centro de Investigaciones Sociológicas, 1981.

Gurrieri, Adolfo, Consideraciones sobre los sindicatos chilenos, Santiago de Chile, Instituto Latinoamericano y del Caribe de Planificación Económica y Social (ILPES), 1968.

Landsberger, Henry, Contemporary Latin American Peasant Movements, Ithaca, Cornell University Press, 1969. 
Medina Echavarría, José, Aspectos sociales del desarrollo económico, serie conmemorativa del XXV aniversario de la CEPAL, Santiago de Chile, CEPAL/ILPES, febrero de 1973.

, La urbanización en América Latina, Buenos Aires, SolarHachette, 1967. , Consideraciones sociológicas sobre el desarrollo económico en América Latina, Buenos Aires, Solar-Hachette, 1964.

O'Donnell, Guillermo, Modernización y autoritarismo, Buenos Aires, Paidós, 1972.

Quijano, Aníbal, "Movimientos campesinos contemporáneos en América Latina”, en S.M. Lipset y A. Solari (eds.), Elites y desarrollo en América Latina, Buenos Aires, Paidós, 1967.

Ratinoff, Luis, "Los nuevos grupos urbanos: las clases medias", en S.M. Lipset y A. Solari (eds.), Elites y desarrollo en América Latina, Buenos Aires, Paidós, 1967.

Redfield, Robert, Peasant Society and Culture, Chicago, The University of Chicago Press, 1956.

Rosenblüth, Guillermo, Problemas socioeconómicos de la marginalidad y la integración urbana: el caso de "las poblaciones callampas" en el Gran Santiago, memoria de grado, Santiago de Chile, Universidad de Chile, Facultad de Ciencias Económicas, Escuela de Economía, 1963.

Soladi, A., R. Franco y J. Jutkowitz, Teoría, acción social y desarrollo en América Latina, México, Siglo XXI, 1976.

Stinchcombe, Arthur L., "Agricultural Enterprise and Rural Class Relation”, en American Journal of Sociology, vol. 67, Chicago, University of Chicago Press, 1961-1962.

Tokman, Víctor, "Dinámica del mercado de trabajo urbano: el sector informal urbano en América Latina”, en Reyes Kaztman (ed.), Fuerza de trabajo y movimiento laboral en América Latina, México, Colegio de México, 1979. 